\title{
Comentarios Extemporáneos: Neruda y el Premio Nobel
}

No hemos leído, como esperábamos, a raíz del Premio Nobel de Literatura, 1971, otorgado a Pablo Neruda, los juicios y comentarios objetivos pertinentes. Neruda no es un escritor que requiere sólo incienso: no lo es nadie. Dadas las características del poeta, el incienso podría servir, en su caso, más que para zahumar al santo, para alejar a los demonios. Un escritor de su talla y a su altura exige y resiste todo tipo de críticas. Cumplida su tarea poética, una de las más extraordinarias del idioma y del siglo, el poeta debe desear una repetición literaria de la dramática escena de Y'uste: asistir a sus propias exequias. Podría pensarse que lo dicho alienta una postulación funeraria, el ensayo de un provisorio De Profundis. Pero tampoco se trata de lamentar una ausencia, sino de festejar la perseverante presencia de un gran poeta. El arte de Neruda muestra un número tal de aristas, valles, cimas y no pocas platitudes, perplejidades, sugestiones y dogmas, que se hace indispensable repensatlos a él y a su obra, para "concientizar" mejor el homenaje que rendimos, no a un affiche publicitario de cierta tendencia política, al uso, ni a un prestigio estético impuesto por circunstancias extraestéticas, sino que nuestra adhesión es justa y razonada. Sería conveniente, en suma, cotejar al político con el poeta, deslindar los campos respectivos, o fundirlos por causa de inseparabilidad si ése fuera el caso.

Tenemos a la vista dos libros excelentes sobre Neruda: el ya clásico de Amado Alonso y el de Emir Rodríguez Monegal. El de Alonso, un estudio metódico, objetivo, estrictamente estilístico, se desarrolla dentro de las predilecciones lingüísticas de su autor; el segundo, inspirado en la conducta de Neruda, deja fluir, o extrae, la poesía emanante de la aventura vivencial del poeta. Pretendemos liberarnos de ambas penetrantes influencias, clarificar nuestra propia visión del personaje y su peripecia literaria y política. 
Aunque sea acoger mezquindades, debemos admitir que, frente al otorgamiento del Premio Nobel, han surgido algunas reticencias postnobelianas. Se ha pretendido vincular la votación que ungió a Neruda con determinado criterio político, proveniente del peso decisorio del grupo comunista en el Parlamento Noruego. Se ha levantado también, como si hubiese sido víctima de un inexistente despojo, el caso de Jorge Luis Borges, que se destaca marcando su condición eminentemente apolítica y burguesa. Tales imputaciones, por ingratas e inoportunas que sean - $-\mathrm{y}$ lo son-, representan un punto de vista que, por la magnitud del galardón y la notoriedad del recipientario, deben ser tomadas en cuenta.

\section{1.-HIJO DE LA FAMA}

Neruda conquista la fama, casi un adolescente, con la edición de Veinte poemas de amor y una canción desesperada, en 1924, cuando él tenía apenas veinte. Precocidad tamaña, sólo en Rimbaud, a quien Neruda admira, tanto como a Lautréamont, otro joven genial, ambos caóticos, desesperados y sin la terca vitalidad de Neruda. Desde ese momento surgieron, como era de esperarse, rivales, émulos y detractores. Uno de los cargos que entonces se le hicieron fue el de supuestos plagios a Rabin. dranath Tagore y a Carlos Sabat Ercasty. No mencionamos esto por tecordar necedades; tampoco para desechar sin más ni más el infundio. La imputación de plagio es vieja, pueril y necia. El propio Neruda ha declarado por escrito su admiración a Sabat Ercasty. El poeta uruguayo cultivaba una poesía que podríamos denominar "civil" y "cósmica"; sus temas eran los grandes elementos del cosmos: el hombre, el mar, la tierra, los montes, la vida. Sabat cultivaba el polirritmo polimétrico con que se ha tratado de imitar en castellano el exámetro clásico y adaptar el verso de Walt Whitman. Neruda se hallaba disputado en aquel su momento augural por contradictorias deidades. De un lado, la musa íntima, sencilla, provinciana, dolorosa y carnal; del otro la musa popular, la de Anarkos, la del grupo "Claridad" (recuérdese Clarté de Barbusse, a que se asimiló fugazmente Anatole France). Claridad fue el título de un periódico y de un grupo literario de la primera postguerra que se transmitió a los jóvenes latinoamericanos seducidos por la problemática social. Se creaton grupos y revistas, con parecidos, si no idénticos propósitos y títulos, entre los estudiantes peruanos (Haya de la Torre fundó y dirigió la revista Clavidald, cuyo priorato cedió, en 1923, a J. C. Mariátegui), así como entre los de Santiago de Chile, Buenos Aires, etc. Los primeros pasos 
literarios de Neruda (quien adopta este seudónimo desde 1920) vacilan entre la proclama y la confidencia. Sus predilecciones literarias seguirán el mismo ritmo. Su obra entera la reflejará hasta hoy.

De esos primeros paśos literatios extractamos algunos hechos poco mencionados, aunque sin duda bastamente conocidos: 1) su escogitación del nombre de Neruda, tomándoselo al poeta centroeuropeo Jan Neruda, 2) su entusiasmo por Sabat Ercasty; 3) su devoción a Walt Whitman; 4) su admiración a Rabindranath Tagore, desde antes de ir a la India, en las magnificas traducciones de Zenobia Camprubí de Jiménez; 5) una traducción juvenil de Páginas escogidas de Anatole France (editadas por Nascimento, de Chile); 6) una traducción de Rainer María Rilke (Les cabiers de Malte Laurids Brigge), hecha en 1926, cuando, gracias a la consagración de Edmond Jaloux, se difundia la ópera omnia del gran escritor checo al francés; 7) una traducción de William Blake después de 1930 y ahora último Romeo y Julieta de Shakespeare. Traducir implica algo más que leer; implica coincidencia, admiración, secreto discipulaje. Destacamos las traducciones de France (en la época de sus más acerbas críticas a la burguesía francesa) y de su franca simpatía a la acracia social, de Rilke, cuya delicadeza no descarta una profunda creencia en la poesía como plena expresión de vida — son reveladoras-. Sin duda, el juicio de lo que debe ser un poeta que formula Rilke en Los cuader. nos... repercutió y ha repercutido hasta hoy en Neruda. Para ser poeta debemos haber visto morir a un hombre, parir a una mujer, llorar a un niño, dice Rilke. Algunas metáforas del primer Neruda, el de Veinte poemas y de Crepusculario, documentan el acatamiento inequívoco y consustancial a tal definición.

Estamos hablando de coincidencias, de analogías, de reminiscencias involuntarias; de eso que, en su reciente libro sobre García Márquez: Historia de un deicidio, llama Vargas Llosa los "demonios personales", los "demonios culturales" y los "demonios históricos" de cada autor.

Con respecto a Neruda, ha predominado la superstición de imaginarlo absolutamente original. Nadie lo es en proporción o medida absoluta. La tradición cultural representa la razón de ser de cada generación, de cada grupo, de cada género, de cada escritor. Pero tampoco existen tradiciones puras, como no hay géneros literarios puros, ni originalidades plenas. Todo es relativo y todo forma parte de una cadena, cuyas cimas o eminencias no se alzan contra las lomas ni contra las platitudes cercanas, sino como consecuencia de éstas y de ésas. 


\section{2.-Dicotomías}

En la obra y vida de Neruda se advierten dicotomías tangibles tales como: amor-protesta, materia-espíritu, intimidad-colectivismo, logos-caos, ternura-dicterio, humildad-soberbia, sensualidad-ascetismo. Reunir tales antinomias que son la vida misma, para fundirlas en una vasta unidad sin contrastes ni matices sería negar la existencia de la poesía. Nadie, ni el mismo Neruda niega el impacto que en su formación literaria ejercio la lectura de Les chants de Maldoror y Les illuminations; por eso, precisamente por eso, la blasfemia de Lautréamont y las maldiciones de Rimbaud, al diluirse en la ternura rural de Neruda, amante del Gitanjali y El jardinero, alcanzan como una dimensión natural, como una solución ideal, los ilímites contornos del surrealismo. La amistad de Neruda con Louis Aragon y Paul Eluard no son fruto exclusivo de consonancias ideológicas que, en el autor de Residencia en la tierra, son superadas por las correlaciones efectivas, por la amistad y por el amor. Fluye de esa soecia, trascenclente, de esa náusea lírica, la respuesta duplica (luz y sombra, basura y estrella, botella y nardo) a los dos Neruda que mazdeistamente disputan, como en las disputas teogónicas, el alma, el arte y la peripecia del poeta.

Segun que triunfe este o aquel aspecto, esta o aquella vertiente de la personalidad nerudiana será el tono de su expresión poética. Alguna vez Neruda permaneció como alelado, guardando conmovedor equilibrio: fue en la primera Residenci甘 en la tierra, donde, como siempre precozmente, alcanza su madurez el autor de El bondero entusiasta. Sucedió alrededor de 1930. Acababa de cumplir los 26 años. Cargado de hombros, fatigados los ojos, como los de un peregrino; la voz recóndida, como la de un mago; el paso largo y lento, como un paquidermo, Pablo Neruda, lejos del erótico ímpetu juvenil, evocaba milagros, angustias y fantasmas. Sin embargo, entonces, precisamente entonces, el amor y el vino, el roble y la amistad se disputaban lo mejor de su inmarcesible y secreta adolescencia interior.

\section{3.-EL AMOR}

El primer Neruda (amor, toronjil, raulí, alcachofa, uva, estrella, mujer) llegó del sur de Chile, aterido por la orfandad materna y herido por la ternura inexausta de un padre maternal, laborioso, que no buscó otra 
mujer, sino otra madre para el hijo huérfano. Este es un estigma espiritual que no se borra fácilmente. La soledad no suele soltar su presa. La cose a puñaladas si es preciso, con tal de prolongarla. Neruda llegó a Santiago ya escritor. Llevaba saturado el olfato con el olor de los bosques de La Frontera, con el sabor de la chicha y el vino propios en los labios; espoleado por dos apetencias incoercibles: amar la vida y dominar la cultura francesa. Lo uno respondía a un sentido vegetal, telúrico; lo otro, a la prefiguración de la cultura del mundo. Quizás podría hacerse otra conjetura al respecto, confirmada por la obra posterior: el campesino, crecido en contacto con la Naturaleza, pero respetuoso de lo estatuido, quería liberarse por la vía de la cultura, su única arma. Neruda no era Vicente Huidobro, que ya despuntaba como poeta culto, parisino y burgués: carecía de sus facilidades de linaje y de dinero. Tampoco poseía el empuje primordial de Carlos Díaz Loyola (Pablo de Rokha), el otro factor de la trilogia poética "Chile 1920", salvo en cuanto a la profesión: maestro. De Rokha nació atropellando a las palabras, a las imágenes, a los hombres y a las cosas. En el más iracundo de sus arrebatos, Neruda no escribiría jamás ni Jesucristo ni Gran temperatura; así como tampoco Horizon Carré ni El ciudadano del olvido.

Haber elegido el francés como objetivo de su maestría en el Instituto Pedagógico de Santiago responde a un profundo escogitamiento. Más tarde, al regreso del periplo por la India, "Neruda agregará a sus medios de comunicación y expresión, un tanto vergonzantemente, el idioma inglés; presumimos que ahora el ruso haya venido a integtar la diáspora expresiva del poeta.

En esa primera etapa el muchacho provinciano, residente oscuro de la modesta calle Nataniel, recorre con ojos de alucinado los mismos barrios que, despectiva y sarcásticamente, recorría por ese mismo tiempo, la sombra del sombrío Esmeraldo, protagonista de El roto de Joaquín Edwards Bello. Se enamora, como tenía que suceder. Como dice en "Farewell" y en el poema "X", se acuesta con mujeres, pero no para concluit así el idilio, saciándose, sino para ratificarlo, acrecerlo y prolongarlo. Neruda ama con más ansia después de la posesión, después del coito, y no, como casi todos los románticos, como un medio de realizarlo, idealizándolo. Los más ardientes poemas de amor de Neruda son los que cantan el deseo satisfecho, a través de lo cual se extiende y ahonda el amor insaciable. Su musa está lejos de ser la del "Eclesiastés": alterando el orden salomónico, Neruda empieza por el "Eclesiastés" y lo transforma en "Cantar de los Cantares". Ello podría indicar una auténtica voluntad de realismo, un romanticismo más humano que el ritual, pues lejos de detenerse 
en la realización inmediata, saca del placer físico fuerza espiritual para crear nuevas quimeras.

\section{4.-UN ROMANTICISMO SUI GENERIS}

Como él es así, partiendo de la lujuria intransferiblemente personal, Neruda se lanza a la plazuela a perseguir otra lujuria, la del pueblo, buscando la justicia, la afirmación de la acracia, que es su verdadera doctrina social. No nos engañemos: en Neruda el poeta ha dominado siempre al político. Por eso, aunque afiliado al comunismo, se muestra, irrevocablemente, un anarquista. Los zumos de la ardiente adolescencia que compartiera con Rojas Jiménez, González Vera, Manuel Rojas, Rubén Azocar, Juan Gandulfo, Eugenio González, y con los reformistas latinoamericanos de 1920, tiene por signo la acracia, la destrucción del orden instituido, el caos, no para recrear otro orden, sino para afianzar la libertad. ¿No coin. ciden acaso por largo tiempo Marx y Bakunin? Neruda ha sido (salvo sus varias concesiones a la diplomacia, o sea, a la burocracia) un libertario permanente. Libertario en el amor, en las ideas, en la estética, en la conducta, en la amistad. De ahí que le sea indispensable, de cuando en cuando, recordarnos y recordarse que es comunista y que cree en la sagrada causa del proletariado.

\section{5.-LA MUJER}

Ningún ser ha influido tanto, ni se ve tan presente en la obra y la vida de Neruda, como la mujer. La mujer, así, a secas. La mujer-sexo e ilusión. La mujer-sexo, no porque sea simple compañera de cópula, sino porque lejos de la mujer-suspiro, sin labios que exhalen el suspiro, deja de ser humano. Neruda es, por antonomasia, un poeta bumano. No le robamos una tilde al título (no escogido por él) del libro póstumo de su amigo y nuestro amigo el gran poeta César Vallejo. También el autor de Trilce se inició (¿persistió?) en la escuela de la acracia, del anarquismo. Cuando quería dar "un pedazo de pan fresco" a todos, "un trozo de pan cocido en el horno de mi corazón"; o cuando, hablando de sus ancianos padres a quienes reencuentra al volver a la casa, dice "son dos caminos blancos, viejos/: por ellos va mi corazón a pie", lo que Vallejo expresa es un sentimiento de humanitarismo primordial. 


\section{6.-LAS ESCUELAS LITERARIAS}

España era en 1931-36 un tremendo campo de experimentación anarquista. Neruda llegó en esos días a Madrid. La Guerra Civil de 1936-38, júzguesela como se la juzgue, fue en gran parte una estupenda y trágica aceptación de un destino individualista, pero, anticapitalista, anticlerical; un individualismo creador.

He aquí otro reto a los clasificadores literarios: ¿qué es Neruda? ¿Modernista, postmodernista, romántico, creacionista, ultraísta, surrealista? Neruda ¿qué? Contestaríamos de inmediato: N-e-r-u-d-a.

Un hombre sensible no puede sustraerse a su corazón, ni al ámbito exterior, en el que está su inteligencia. El corazón empuja hacia el romanticismo, es decir, hacia las ardientes confidencias, hacia la intimidad en carne viva, hacia cierta dulce melancolía, hacia el amor. Ya Darío, el más grande poeta del idioma, ha dicho: "quien que es no es romántico". No sólo la primera parte de la obra de Neruda, sino la más reciente, rezuma sentimentalismo confeso y pánico amor. ¿No ha dicho él, últimamente, después del Premio Nobel, que toda su poesía es de amor? Lo es y, a despecho de los "camaradas" militantes, lo es hasta cuando versifica sobre hechos políticos. Ese romántico "Canto de amor a Stalin. grado", ese apasionado libro de "versos al capitán" así lo demuestran.

Por otra parte, en esa propia "rendición del espíritu" se debe distinguir las formas y modos de hacerlo. Algunos sostienen que no son ya modos románticos sino ultraístas, postmodernistas y suprarrealistas. Las definiciones obliteran demasiado a los críticos, y peor aún, a los lectores y a los alumnos de literatura. ¿Por qué es Neruda un postmodernista? Pues, porque su aparición es cronológicamente posterior al auge modernista $y$, siendo así, su poesía deberá contener los elementos añadidos na. turalmente al modernismo; además de la melodía y el colorido solar, habría que considerar los prosaísmos deliberados. En verdad, todo eso significa un inevitable tributo al cambio de temple que nos imponen el tiempo y sus novedades. En cuanto a un Neruda creacionista, descartémoslo por respeto al ruidoso pleito Huidobro (creacionista mayor). Neruda (nerudiano insobornable). Es cierto que la poesía de Neruda se perfila entre el auge del ultraísmo y la confirmación del surrealismo, es decir, entre 1918 y 1928, pero también es cierto que la comprende, en su más definitoria etapa, la aparición del existencialismo. De todo eso podría surgir un monstruoso caos de tendencias, inaplicable siquiera a la inter. pretación de un solo poema de Neruda. El poeta compone y crea sobre 
la base de experiencias personales y sólo a veces se somete pasajeramente a un planteo ideológico, visiblemente externo, alienante y alienado. Todo lo demás, lo mayor y más significativo, refleja su propia personalidad. Por eso, si se prefiriera no usar a propósito de Neruda el vocablo ro. manticismo, a causa de sus múltiples implicancias, sería plausible utilizar "personal" que, en muchos aspectos, comprende su obra. Hay, empero, un elemento del cual no se puede prescindir: toda la poesía de Neruda (y su biografía, acusa la permanente y prevaleciente presencia de una mujer. No decimos de esa o aquella mujer, insistimos: de una mujer. Inclusive en las de mayor entrega revolucionaria o partidaria, aparece como numen tutelar de una mujer. La galería que exhiben los poemas de Neruda es larga: amigas, colegas, camaradas, amantes, esposas, mujeres. Una de las más atriesgadas emptesas, la de fletar los cuadernillos con can. tos al pueblo español, durante la guerra civil, los realiza el poeta en com. pañía de Delia del Carril, la inolvidable "hormiguita" de aquellas terribles vigilias, y con Nancy Cunnard, una inglesa apasionada de la revolución española, socia de una gran firma capitalista, la Cunnard Line, y, por tanto, éticamente anticapitalista... En la campaña por el Frente Popular de Chile y de ayuda al pueblo español, tiene como coprotagonistas a Amparo Momm, la compañera de Raúl González Tuñón, a María Luisa y Blanca Bombal, Luz Rivas, Mireya Latorre, Laura Rodig, María Valencia. En la etapa de la madurez aparece la figura de Matilde Urrutia, ante quien el poeta se rinde, confesándose públicamente enamorado. Para ella son los Cien sonetos de amor y otros cantos recientes. Matilde es la única mujer que recibe directo y pleito homenaje de Neruda. Aparte de las razones intimas para proceder así, resulta natural que, al borde de la jugosa y serena senectud, la más hermosa y dorada edad glorificada en sus inconmutables esencias por Cicerón, deberán ser más rotundas la profesión de fe y la confesión de amor. Su expresión es como un hermoso y angustioso mensaje, el más hondo de todos, como una botella al mar, al mar de la posteridad.

\section{7.-Poesía política}

Según muchas versiones, Neruda es un poeta revolucionario, un poeta comunista, un poeta de masas, un gonfalonero de la nueva sociedad.

Lo último es bastante exacto. Porque la nueva sociedad, reaccionando contra el convencionalismo de la precedente, proclama todo lo opuesto a los ideales de la que vivimos. Proclama contra liberalismo, autorita- 
rismo; contra capitalismo, socialismo; contra Dios, la actacia celestial; con. tra la institución, la secta; contra libertad, libertinaje; contra planeaciones totalitarias y jerárquicas dogmáticas, la acracia, contra burguesía, el proletariado; contra gerontocracia, la efebolatría; contra la familia, el "hippismo"; contra la moral cristiana, el moralismo pagano; contra el clasicismo, la caricatura de los clásicos. Ideológicamente todos los prejuicios y rutinas son relativamente fáciles de vencer, excepto los que afectan a la familia y al amor. Neruda enuncia -y acaso practicó- lejos de obscenidades y de pornografía, con nobles palabras ceremoniales y conducta alegre, la vida sin trabas, pero siempre con una limitación, el amor $-\mathrm{y}$ el amor heterosexual- No hay en sus poemas ninguna sombra de amores unisexuales o incestuosos. Ama según la naturaleza. Usa total libertad en sus modos y medios, no en sus objetivos. De ahí que ame a las mujeres, defienda a los hombres y rinda culto a Noé, salvador de la especie humana con el Arca y con la vid.

En cambio ¿revolucionario? Si por revolución se entiende el permanente ataque a ciertas jerarquías y ciertos partidos, tal vez sí; más, si por revolucionario se reconoce al tenaz artífice de un orden nuevo, el consciente destructor de una sociedad podrida, entonces no. Porque Neruda participa de los detectados usos de esta sociedad, y no lo niega; y porque en muchos poemas cantó a los ídolos que después ha tratado de quemar. Un poeta se diferencia básicamente de un político en que a aquél no se le pueden admitir treguas ni transacciones. Los políticos funcionan como instrumentos de lo posible; los poetas, como heraldos de lo absoluto. Si un poeta se rẹsigna a actuar como político, habrá dejado de ser lo primero sin llegar a lo segundo. Es lo que sucede con muchas partes del Canto general: no, por muy Neruda que sea su autor, nadie podrá convertir en materia poética a políticos como los que ahí se excecran. Gabriel González Videla, Arturo Alessandri; el General Ibáñez (bajo cuya primera dictadura salió Neruda como Cónsul de Chile), no son ni serán sujetos de poesía, ni es poesía el vituperio rítmico a "los Dámasos" y otros colegas. En vano se invocará los ejemplos de Dante y Víctor Hugo. La Divina comedia tiene tanto del cantar de gesta de una raza y de un idioma como de respuesta a un ideal trascendente, preciso, sostenido por el pulso firme y de un vate realmente epocal. Les chatiments reflejan tal furia, tal desesperación, tal exasperación contra el exilio y en forma tan desgarrada, que, lejos de incitarnos a odiar a Napoleón III, nos conducen a levantar a su víctima, Víctor Hugo dueño de un verso inexpugnable. No es lo mismo atacar a un Médici o a un Bonaparte que a un líder provinciano e indefinido. No es lo mismo disparar contra un león que contra 
un gato. La poesía reside no sólo en la expresión, sino en su origen y su meta.

Por otra parte, Neruda, comunista sólo después de la caída de la repú. blica española, esto es, desde 1938, no ha conocido las horas tormentosas de verdadera petsecución y la lucha directa. El partido comunista chileno, con sagaz percepción del porvenir y del valor del poeta, le aseguró siempre un lugar prominente, hasta durante la pintoresca y lamentable persecución de que le hizo víctima un régimen desbrujulado. Perseguir a un gran poeta nunca dio réditos al persecutor; ser el partido de un insigne perseguido, contribuye inequivocamente a la mayor gloria del par. tido y del perseguido: ganan los dos. El Premio Stalin fue otro acicate sobreviniente y merecido. Nada de eso torció el rumbo auténtico de la poesía nerudiana. Cierto: pagó su cuota rimada a la URSS y al PC, pero no comprometió su libertad de amar, cantar, reunirse, vivir, dialogar, viajar. Por causa de su poesía y de su don de amistad, de su capacidad de amor, Neruda pudo transitar, transitó y transita y se exhibe en las asambleas soviéticas, en los cenáculos húngaros, en las universidades norteamericanas, en las reuniones profesionales brasileñas, en México, París, Santiago, Lima, Washington, Nueva York, Praga, Londres, no importa el tipo de gobierno imperante ni la clasificación ideológica de los invitantes. Desde ese punto de vista ha representado y representa un voto singular, una especie de voto discordante y personal como el de un nuevo Juez Holmes, no en los tribunales washingtonianos sino en el parnaso mundial.

Nadie pregunta a Neruda cuál es su filiación, aunque estamos seguros de que contestaría positivamente: comunista. Empero, por respeto a su indiscutible y merecido prestigio, debemos ahorrar una vana discordia. De todas maneras, aun dentro del más hermético marxismo, Neruda destaca su presencia mediante un rasgo de amor: amor al pueblo, amor al pobre, amor al humilde, amor a la belleza, amor al amor. Esa es su clave individual y colectiva. De ella mana su poesía apasionada, triste, turbulenta, hecha de angustia, armonía y desesperación.

\section{8.-UN APUNTE SOBRe el estilo}

Los últimos libros de Neruda, desde 1960, son repetitorios, y es natural: quien crea un estilo acaba siendo presa de él: es el precio de la personalidad. Se dice también que las Odas elementales son distintas, en forma y fondo, a sus poemarios anteriores. Ciertamente aumenta la 
simplicación limpiando al estilo de excrecencias. No es raro. Todo escritor alcanza, en la medida que crece hacia adentro, una mayor sencillez. Los clásicos lo son, no tanto por paradigmáticos, sino por diáfanos, por el ahorro reproductivo de su expresión según diría un economista al uso. Son pocos los casos que, como Góngora, aumentan en años y en supuesta oscuridad, aunque debiéramos denegar sin titubeos tal carácter: la llamada "oscuridad" del Góngora de Las soledades depende de la avaricia con que (pese la opulencia de color y fantasía) emplea los giros sintácticos. La aliteración, la lítote y la metonimia se ajustan allí tanto al cuerpo poético, que se los confunde con la piel, son parte del cuerpo. Las mis. mas paráfrasis gongorinas, compendian, sintetizan. De tal manera, las Odas elementales y aun los juegos verbales del Fulgor y muerte de Joaquin Murieta de Neruda, revelan insultante desprecio por las galas ver. bales; dicen lo que buscan decir, en el menor número de palabras posible, con la misma usura verbal de Rubén Darío después de Cantos de vida y esperanza, como el Juan Ramón Jiménez de Arias tristes, y, sobre todo, de los últimos libros...; como el Chocano de los Nocturnos, todavía sobrados de elocuencia.

En cuanto a los temas, Neruda persiste en el "cosalismo" primitivo (poemas a la cebolla, al apio, a la madera, al vino, etc.) iniciado en la primera Residencia en la tierra. Ni siquiera cambia el endecasílabo. Aunque los versos se quiebran en aparentes cortas frases líricas (versos de arte menor) de cuatro, cinco, seis, siete sílabas, no bien leemos de corrido nos percatamos de que $7+4$ da 11 ; de que $6+5$ da 11 , de que $4+7$ da 11 , de que $3+3+5$ da 11 , y así volvemos a las viejas combinaciones métricas del Neruda de los primeros libros, no siempre exacto (para qué negarlo), pero como todo poeta culto, con una invencible tendencia ya a hablar, si no en romance, sí en endecasílabo italiano y en alejandrino francés. Las fallas métricas, es decir, el empleo de una sílaba más o menos, son en Neruda, como en Gabriela Mistral, fruto de deliberada arritmia, sin complicaciones con la rima: la arritmia versifical se disfraza de revolucionaria desde el versolibrismo de Banville. Arritmia, fenómeno cardíaco, de cardiología literaria en este caso.

9.-PoETA de américa y de sí Mismo

Walt Whitman, ese imperdonable corruptor de la lírica moderna (Ezra Pound ha empezado a birlarle el calificativo), se ha cantado "a sí mismo" y ha cantado "al cuerpo eléctico"; también al "capitán", también 
a Lincoln, como Neruda. Whitman enseñó el nudismo sentimental, la impudicia de confesión a grito herido, sin sollozos ni suspiros; Whitman, apresurado y enérgico, prefirió enumerar a describir, no tuvo tiempo para combinar los elementos que simplemente yuxtapuso. Esta técnica fue usada, con excesiva elocuencia, por Chocano, quien fue, no lo olvidemos neciamente, el que dio consistencia a la idea de crear la dignidad de un honorífico "Poeta de América". Chocano aceptó el reto de Rodó, quien negó tal título a Rubén Darío, y trató de convertirlo en realidad. Neruda, huaso astuto, ha esquivado el comprometedor epíteto, mas no el pro. pósito. Chocano entendió América como un inmenso paisaje natural (romanticismo) poblado de historia, es decir de pasado (romanticismo), pero expresado en tono oratorio y sentencioso (parnasianismo), poniendo en circulación los nuevos términos remozados por Dario, Rueda y Lugones (modernismo). Remitimos al lector curioso a nuestro Aladino o vida y obra de I. S. Cbocano (México, 1960), para no apelar a prolongadas trascripciones, tal como las hemos eliminado adrede en lo referente a Neruda.

América era para Chocano historia y paisaje. Se acercó a la época contemporánea sólo a través de su propia peripecia y por medio de la Revolución Mexicana. Sin que ésta ejerciera sobre él la presión sanguí. nea y emocional que la Guerra Civil española ejerció sobre Neruda, la Revolución Mexicana concluyó con la paisajistica brillante y abrió el camino a la intimidad del poeta, a la iracundia, al asonante y la melancolía. A su turno, Neruda ha tratado de interpretar y exaltar episodios políticos y episodios de rebeldía, en el Canto general, y aún en el Joaquin Murieta. El libro de su autobiografía no esconde su fruición al sentirse en lírica compañía de levantiscos, bien sea que se trate de insurrectos políticos (revolucionarios), bien sea insurrectos sociales (bohemios, bandoleros y contrabandistas). Chocano también vivió esos dos modos de insumisión y protesta: fue rebelde, medio bandido, hombre de prensa. Por eso no se ocupó de la revolución en sus poemas. Neruda, que ha sobrellevado predominantemente una vida de bohemio sin estrecheces, y de diplomático sin mayores responsabilidades, tenía que exaltar con el verbo la insurrección que no practicaba con los hechos. Volvemos a una observación profunda, imperecedera de Oscar Wilde en el prólogo de El retrato de Dorian Gray: el mundo se divide en dos clases de hombres: los que viven los poemas que no pueden escribir, y los que escriben los poemas que no alcanzan a vivir. Hecho este distingo, con sus correspondientes descuentos conceptuales y factuales, respetemos a cada cual en su estilo, al uno perorando en verso desde la tribuna, al 
otro musitando junto a la mesa del café. Así, ambos, Chocano y Neruda (los "chocaneros" y los "nerudones" diria ácidamente Juan Ramón), han tratado de captar las esencias de América en sus respectivas obras poéticas. Hoy el gusto artístico desconfía del discurso, aunque use la proclama; amamos la sordina, la "coloquialidad": Neruda prevalece y prevalecerá hasta que, como tiene que ocurrir, cambien las aficiones de críticos y lectores, y Hugo se sobreponga a Verlaine y el divino Herrera a Quevedo.

Existen otros campos de coincidencia entre los dos poetas nombrados. Ninguno de ellos ha hecho otra cosa que poetizar sus respectivos actos cotidianos. Tal como Unamuno, con ejemplar franqueza, se confiesa día a día en su Cancionero, y así como Vallejo en Trilce, la poesía de Neruda no es otra cosa que su autobiografía en progreso ("work in progress" llamaba Joyce a los primeros capítulos de su Ulises). De ahí que las alusiones concretas con que a menudo interrumpe Neruda el tono abstracto de sus poemas, sean tan vivaces, tan provocativas. Parecen caricaturas, porque nacen de una experiencia inmediata. Cualquiera, con algún conocimiento del oficio, puede pintar un retrato: la caricatura exige concordancia efectiva, observación directa.

Por todas estas consideraciones, que sólo recogen una parte de las que venimos acumulando desde que, en 1924, leímos por primera vez a Neruda, y desde que, en 1937, anudamos con él una amistad que ha resistido muchas discrepancias y resfríos, nos alegramos profunda y en. trañablemente, como colegas en el duro y dulce oficio de escribir, por la consagración "nobeliana" de Pablo Neruda, el más grande y más intenso, más humano y más universal de los poetas que todavia sufren y gozan, aman, beben y predican, sueñan y ríen, comen y callan $-\mathrm{y}$ todo eso (hasta el callar y el yantar) en castellano, idioma que él, como muchos americanos, enriquecemos día a día, desde la llanura y desde el Parnaso, desde la iliteralidad y desde el cultismo, afirmándonos en el destino y el propósito de hablar por tantos y tantos que enmudecen; de maldecir por los tantos y tantos que se humillan; de amar y reír por tantos y tantos que odian, gruñen y desaparecen.

\section{LuIS Alberto SÁNCHez}

Lima, marzo, 1972. 
